\title{
Praktische Notiz.
}

Seit etwa zwei Jahren bediene icli mieh bet Furunculose rn.it Vorth,eiï der Darreiohung vón Bierhefe. Zuerst hingewiesen war icli hierauf durch eine Notiz in einer amerikanischon Zßitung und orfuhr dann, dass das-Mittel, zu diesem Z $\lambda$ veck angewendet, in Laienkreisen nieht unbekannt sei. Da das Fermentum Cerevisiae sehvn seit lange unserm A.rznoischatz an-gehört und als vollständig unschädlich, wenn attch wegen mangelnder Indication ausscr bei Scorbut fur ol > solet gegolten hat, so stand einem Ver-such nichts im Wege. Bei nunmehr über dreissig Personen ist es mir seit-lier gelungen, abschliessende Aufzeichnungen festzustellen und in alien dieseit Fallen $\Lambda$ var der Erfolg unverkennbar, die Wirkung rneist eine ersichtlich causal-curative. Gegeben wurden gewöhnlich dreimal tüglich zwischen dens Mahlzeiten je ein Esslöffel der sogen. Rein-Cultur (wie man si·e in jeder besseren Brauerei erhält) und zwar in dünnem Thee oder Bier. Letztere« $\bullet$ eignet sich des Geschmacks wegen am besten. Störende Nehcnwirkungen liessen sicli nicht erkennen. Ab und zu wurde über leichtes Aufstossen oder-Bläl·umgen geklagt. - Der Einfluss auf die Besserung ist meist sogleich deutlich hervorgetreten. Die vorhandenen Furunkel heilten ab. Nouc kaineni zuerst spärlicher, dann gar niclit mehr zum Vorschein und zwar bei Patienten, · die zuvor Monate, auch Jalire an fortwährenden Nachschübcn laborirt hatten.. , lcdenfalls ermuthigen die bislierigen Beobachtungen zu weiteren Versuchen. und haben bier Mittheilung gefunden, um solchen anzuregen.

Die theoretische Erklärung steht nocli aus. * Eine directe Eimvirkung der Hefe auf die Staphylococcen kann niclit olme Weiteres angenommen $\Lambda$ verden. $\Lambda$ Venigsten haben bacteriologisclie Prüfungen, welche $\mathrm{au}^{3 / 8} \mathrm{~s}$ mein Anregung Herr Dr. Lomry in nieinem Laboratorium angestellt hat, keinerlei $\Lambda$ Vachsthumshemmung der Bacterien-Culturen durch Hinzufügung von Bier hefe zu Wege gebracht. Wahrschcinlich liegen also dem Verhalten der beiden antagonistischen Factoren im Organismus complicirtere Verhältnis $1 / 8 \mathrm{e}$ zu Grunde, deren gewiss interessantes Studium sich wohl der Mühe verlohnen dürfte. Einstweilen steht nichts fest, als die practisch verwerthbare Erfahrung von dem günstigen Einfluss dor einfachen Bierhefe auf FurunkelEruptionen. Lassar. 